Article

\title{
Investigation of the Effect of Spin Crossover on the Static and Dynamic Properties of MEMS Microcantilevers Coated with Nanocomposite Films of $\left[\mathrm{Fe}(\mathrm{Htrz})_{2}(\mathrm{trz})\right]\left(\mathrm{BF}_{4}\right) @ \mathrm{P}(\mathrm{VDF}-\mathrm{TrFE})$
}

\author{
José Elías Angulo-Cervera ${ }^{1,2}\left(\right.$, Mario Piedrahita-Bello ${ }^{1,2}$, Fabrice Mathieu ${ }^{2}$, Thierry Leichle ${ }^{2,3}$, Liviu Nicu ${ }^{2}$, \\ Lionel Salmon ${ }^{1}{ }^{\circ}$, Gábor Molnár ${ }^{1, *}$ and Azzedine Bousseksou ${ }^{1, *}$ \\ 1 Laboratoire de Chimie de Coordination, CNRS \& University of Toulouse, 205 Route de Narbonne, \\ F-31077 Toulouse, France; janguloc@laas.fr (J.E.A.-C.); mario.piedrahita@lcc-toulouse.fr (M.P.-B.); \\ lionel.salmon@lcc-toulouse.fr (L.S.) \\ 2 Laboratoire d'Analyse et d'Architecture des Systèmes, CNRS \& University of Toulouse, 7 Avenue du Colonel \\ Roche, F-31400 Toulouse, France; fmathieu@laas.fr (F.M.); leichle@laas.fr (T.L.); nicu@laas.fr (L.N.) \\ 3 Georgia Tech-CNRS International Research Laboratory, School of Electrical and Computer Engineering, \\ Atlanta, GA 30332, USA \\ * Correspondence: gabor.molnar@lcc-toulouse.fr (G.M.); azzedine.bousseksou@lcc-toulouse.fr (A.B.)
}

check for updates

Citation: Angulo-Cervera, J.E.; Piedrahita-Bello, M.; Mathieu, F.; Leichle, T.; Nicu, L.; Salmon, L.; Molnár, G.; Bousseksou, A. Investigation of the Effect of Spin Crossover on the Static and Dynamic Properties of MEMS Microcantilevers Coated with Nanocomposite Films of $\left[\mathrm{Fe}(\mathrm{Htrz})_{2}(\operatorname{trz})\right]\left(\mathrm{BF}_{4}\right) @ \mathrm{P}(\mathrm{VDF}-\mathrm{TrFE})$ Magnetochemistry 2021, 7, 114. https://doi.org/10.3390/ magnetochemistry7080114

Academic Editor: Zoi G. Lada

Received: 28 June 2021

Accepted: 26 July 2021

Published: 9 August 2021

Publisher's Note: MDPI stays neutral with regard to jurisdictional claims in published maps and institutional affiliations.

Copyright: () 2021 by the authors. Licensee MDPI, Basel, Switzerland. This article is an open access article distributed under the terms and conditions of the Creative Commons Attribution (CC BY) license (https:// creativecommons.org/licenses/by/ $4.0 /)$.

\begin{abstract}
We used a spray-coating process to cover silicon microcantilevers with ca. $33 \mathrm{wt} \%$ $\left[\mathrm{Fe}(\mathrm{Htrz})_{2}(\operatorname{trz})\right]\left(\mathrm{BF}_{4}\right) @ \mathrm{P}\left(\mathrm{VDF}_{70}-\mathrm{TrFE}_{30}\right)$ nanocomposite thin films of $1500 \mathrm{~nm}$ thickness. The bilayer cantilevers were then used to investigate the thermomechanical properties of the composites through a combined static and dynamic flexural analysis. The out-of-plane flexural resonance frequencies were used to assess the Young's modulus of the spray-coated films (3.2 GPa). Then, the quasi-static flexural bending data allowed us to extract the actuation strain $(1.3 \%)$ and an actuation stress (7.7 MPa) associated with the spin transition in the composite.
\end{abstract}

Keywords: spin crossover; MEMS; mechanical properties

\section{Introduction}

The molecular spin crossover (SCO) phenomenon displayed by some transition metal complexes refers to the reversible switching between the low spin (LS) and high spin (HS) electronic configurations of the central metal ion-under the influence of an external stimulus (e.g., temperature, pressure, light irradiation, ... ) [1-4]. Due to the strong electron-lattice coupling, SCO materials are known to display a considerable volume change across the spin transition [5-7], which can be exploited in mechanical actuator devices [8-17]. In this context, an interesting asset of molecular SCO materials is that they can be operated at reduced size scales [18]. To explore the actuating properties of SCO complexes at the micro-nanometer scales, thin SCO films have been recently deposited onto moving parts of microelectromechanical systems (MEMS). The term of MEMS refers to a miniaturized device, which consists of both mechanical and electronic components with feature sizes at the microscale. In a broad sense, MEMS devices comprise microfabricated sensors, actuators and electronics that function as integrated systems. MEMS devices have significant impact in modern technology, for example in telecommunication and information technologies. Importantly for us, this class of sensitive micromechanical devices can provide quantitative information on the mechanical and actuating properties of SCO films.

Manrique et al. reported on the first SCO-MEMS [11], which consisted of a $200 \mathrm{~nm}$ film of the SCO complex $\left[\mathrm{Fe}\left(\mathrm{H}_{2} \mathrm{~B}(\mathrm{pz})_{2}\right)_{2}\right.$ (phen)] (pz = pyrazol-1-yl, phen = 1,10-phenanthroline) deposited by thermal evaporation on a silicon microcantilever. The latter was associated with a highly sensitive integrated piezoresistive detection system. The spin crossover was triggered by light irradiation (LIESST effect) at $40 \mathrm{~K}$, which has led to a sizeable and 
reversible shift in the resonance frequency of the cantilever. This resonance shift was quantitatively linked to the changes in thickness, density and Young's modulus of the film upon the SCO. In the continuity of these efforts, the microcantilevers were coated with a $140 \mathrm{~nm}$-thin film of the $\left[\mathrm{Fe}\left(\mathrm{HB}(\mathrm{tz})_{3}\right)_{2}\right]$ complex (tz = triazol-1-yl) [12]. Upon the SCO, changes in the resonance frequency and damping (dynamic response) as well as of the tip position (static response) of the cantilever could be clearly observed. In a follow-up work, these data were extracted and combined with mechanical measurements on bulk $\left[\mathrm{Fe}\left(\mathrm{HB}(\mathrm{tz})_{3}\right)_{2}\right]$ samples, leading to the assessment of the full set of elastic constants of the compound [14]. In a similar approach, Urdampilleta and co-workers [15] drop-casted different SCO complexes over a polymer-based, soft MEMS cantilever, and witnessed an upshift of the resonance frequency when switching from the low to the high spin state. They attributed this behavior to surface stress effect. Finally, $\left[\mathrm{Fe}(\mathrm{Htrz})_{2}(\operatorname{trz})\right]\left(\mathrm{BF}_{4}\right)$ (Htrz $=1,2,4-4 \mathrm{H}$-triazole, $\operatorname{trz}=1,2,4$-triazolato) coated silicon cantilevers were investigated by Dugay et al. [16], who reported on a thermal hysteresis of the cantilever resonance frequency, which closely matched the hysteresis loop associated with the SCO.

In addition to pure SCO materials, MEMS were also coated by SCO@polymer composite films. A dispersion of $\left[\mathrm{Fe}(\mathrm{Htrz})_{2}(\mathrm{trz})\right]\left(\mathrm{BF}_{4}\right)$ nanoparticles in the epoxy polymer SU8 was spray-coated over a silicon microcantilever [13]. Actuation induced by the thermal spin transition has led to a work density of $140 \mathrm{~mJ} / \mathrm{cm}^{3}$ (see also Table 1), representing considerable performance metrics compared with other bending actuator technologies. The key interests of this SCO-composite spray-coating approach are: (1) the seamless integration of high topography micro/nanostructures, as well as (2) its versatility, enabling for deposition of various combinations of SCO particles and polymers. In the present work, we took advantage of the versatility of this method to spray-coat $\left[\mathrm{Fe}(\mathrm{Htrz})_{2}(\operatorname{trz})\right]\left(\mathrm{BF}_{4}\right)$ nanoparticles embedded in a poly(vinylidene fluoride-trifluoro-ethylene) $\mathrm{P}(\mathrm{VDF}-\mathrm{TrFE})$ matrix over MEMS cantilevers. SCO@P(VDF-TrFE) composites have been recently investigated by some of us for the interesting electromechanical couplings between the components $[19,20]$. As a first step towards the exploration of these couplings at the micro- and nanometric scales, we present here an investigation of the thermomechanical properties of $\left[\mathrm{Fe}(\mathrm{Htrz})_{2}(\operatorname{trz})\right]\left(\mathrm{BF}_{4}\right) @ \mathrm{P}(\mathrm{VDF}-\mathrm{TrFE})$ nanocomposite films, deposited on a MEMS cantilever.

Table 1. Mechanical and actuation properties of $\left[\mathrm{Fe}(\mathrm{Htrz})_{2}(\operatorname{trz})\right]\left(\mathrm{BF}_{4}\right) @$ polymer composite films.

\begin{tabular}{|c|c|c|}
\hline & $\begin{array}{c}{\left[\mathrm{Fe}(\mathrm{Htrz})_{2}(\mathrm{trz})\right]\left(\mathrm{BF}_{4}\right) @} \\
\text { P(VDF-TrFE }) \\
\text { [This Work] }\end{array}$ & $\begin{array}{c}{\left[\mathrm{Fe}\left(\mathrm{Htrz}_{2}(\operatorname{trz})\right]\left(\mathrm{BF}_{4}\right) @\right.} \\
\text { SU8 [13] }\end{array}$ \\
\hline Length, $l(\mu \mathrm{m})$ & 150 & 840 \\
\hline Si cantilever thickness, $t_{s}(\mu \mathrm{m})$ & 2 & 20 \\
\hline Composite film thickness, $t_{f}(\mu \mathrm{m})$ & 1.5 & 3.5 \\
\hline Width, $w(\mu \mathrm{m})$ & 50 & 100 \\
\hline Particle weight fraction, $f(w t \%)$ & 33 & 30 \\
\hline Density, $\rho\left(\mathrm{kg} / \mathrm{m}^{3}\right)$ & 1800 & 1400 \\
\hline Tip deflection at SCO $\delta(\mu \mathrm{m})$ & 0.88 & 3.65 \\
\hline Cantilever curvature due to SCO $k\left(\mathrm{~m}^{-1}\right)$ & 80 & 10 \\
\hline Actuation strain due to SCO, $\varepsilon_{S C O}(\%)$ & 1.3 & 1.0 \\
\hline Actuation stress due to $\mathrm{SCO}, \sigma_{S C O}(\mathrm{MPa})$ & 7.7 & 43 * \\
\hline Young's modulus, $E(\mathrm{GPa})$ at $40^{\circ} \mathrm{C}$ & 3.2 & - \\
\hline Young's modulus, $E(\mathrm{GPa})$ at $95^{\circ} \mathrm{C}$ & 0.5 & 3.2 \\
\hline Work density due to $\mathrm{SCO}, w / v\left(\mathrm{~mJ} / \mathrm{cm}^{3}\right)$ & 40 & 140 \\
\hline
\end{tabular}

\section{Results}

In order to reduce particle aggregation effects during the spray-coating process, we opted for a reverse micelle-based particle synthesis method, which has been already described in [21]. The surfactant used in the synthesis enrobes the $\left[\mathrm{Fe}(\mathrm{Htrz})_{2}(\operatorname{trz})\right]\left(\mathrm{BF}_{4}\right)$ 
particles and reduces their aggregation [22]. TEM analysis of the particles revealed ca. $1000 \mathrm{~nm}$ long and $200 \mathrm{~nm}$ large rod-shaped particles. Films of the pure P(VDFTrFE) copolymer (with $70 \% / 30 \%$ monomer ratio) and nanocomposite films of $33 \mathrm{wt} \%$ $\left[\mathrm{Fe}(\mathrm{Htrz})_{2}(\operatorname{trz})\right]\left(\mathrm{BF}_{4}\right) @ \mathrm{P}(\mathrm{VDF}-\mathrm{TrFE})$ with $1500 \mathrm{~nm}$ thickness were spray-coated on silicon microcantilevers, which were analyzed for their static and dynamical behavior both before and after the coating process.

Figure 1 shows a photograph and scanning electron microscopy (SEM) images of the SCO-MEMS device, revealing a smooth, continuous and defect free coating of the cantilevers. It is interesting to notice that the SEM images depict a homogeneous deposit even over the micro-wires that bond the MEMS system to the PCB (printed circuit board) and the PCB itself, proof of the capability of this method to deposit conformal thin films on three-dimensional structures.

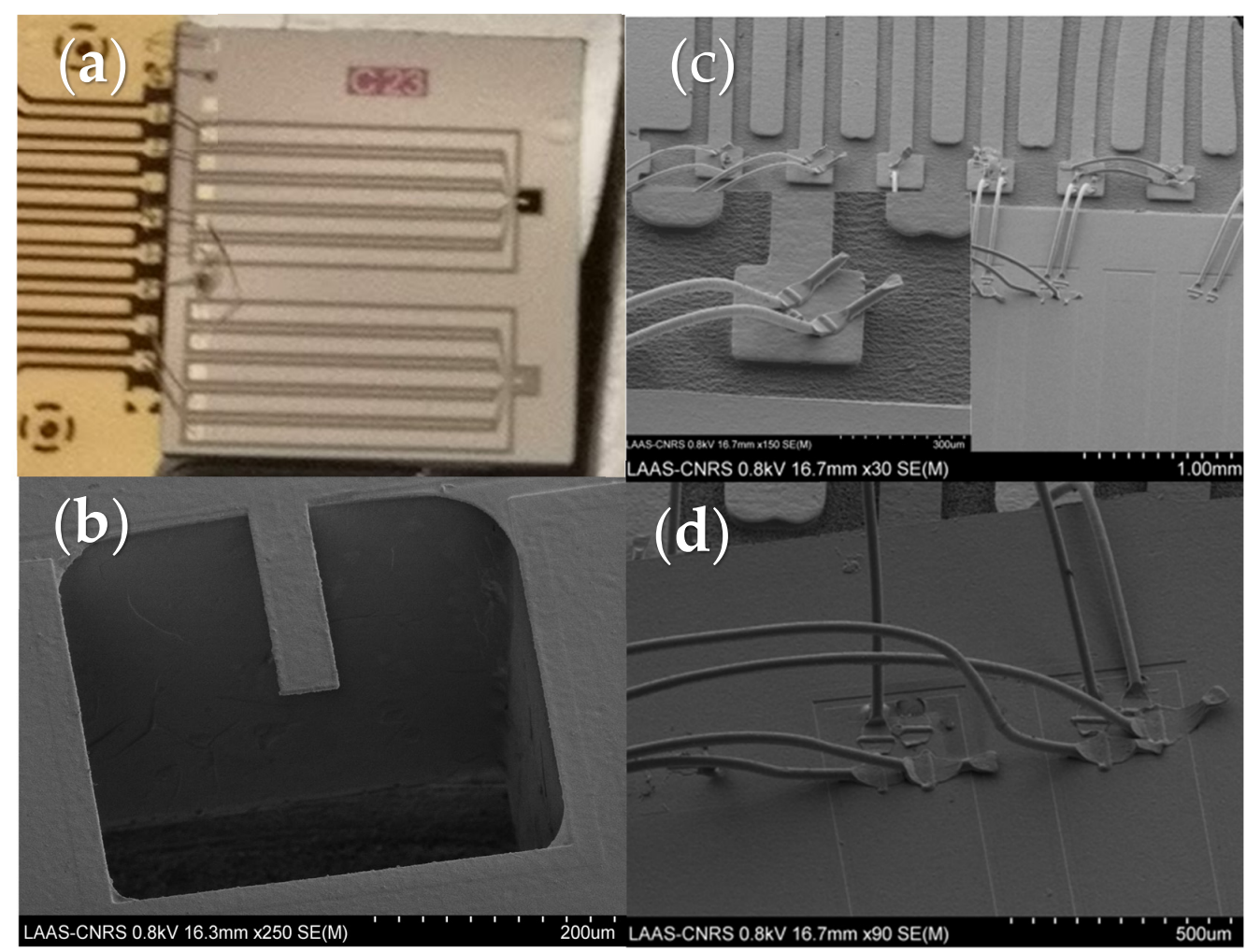

Figure 1. (a) Photograph of the MEMS device. (b) SEM image of a silicon micro-cantilever coated by the $\left[\mathrm{Fe}(\mathrm{Htrz})_{2}(\mathrm{trz})\right]\left(\mathrm{BF}_{4}\right) @ \mathrm{P}(\mathrm{VDF}-\mathrm{TrFE})$ composite film. $(\mathbf{c}, \mathbf{d})$ Larger scale SEM images showing the MEMS, the PCB and the bonding wires, which are also uniformly coated.

MEMS can be operated in static or dynamic regime (or a combination of both) [23,24]. In the static mode, the MEMS is used to transform a static deformation induced by an external perturbation into a variation in electrical current or voltage (or vice-versa). In the dynamic mode, the cantilever is oscillated in resonance conditions and the MEMS is used to track changes induced by an external perturbation on the resonance frequency $\left(f_{r}\right)$ and the damping of the oscillation. The damping is characterized by the quality factor $(Q)$, which can be defined as the ratio of $f_{r}$ and the full width at half maximum (FWHM) of the resonance peak. Higher $Q$ indicates a lower rate of energy loss (per oscillation cycle) and allows for higher sensitivity.

Figure 2a shows the change in the resonance curve of the micro-cantilevers due the deposition of the $1.5 \mu \mathrm{m}$-thick composite film. One can depict a decrease in the resonance frequency by ca. $13 \mathrm{kHz}$ and an important broadening of the peaks (i.e., an overall increase in $Q)$. The resonance shift is mainly related to the addition of extra mass to the cantilever, whereas the change in the quality factor stems chiefly from a change in the elastic properties 
of the resonator with the addition of the SCO@P(VDF-TrFE) coating. We also acquired resonance curves of the coated cantilever at $90{ }^{\circ} \mathrm{C}$ on heating as well as on cooling back from $130{ }^{\circ} \mathrm{C}$. Since $90^{\circ} \mathrm{C}$ falls in the middle of the SCO hysteresis (vide infra), the heating (and cooling) spectrum corresponds to the LS (resp. HS) state of the particles in the composite. As displayed in Figure $2 \mathrm{~b}$, the resonance is substantially downshifted in the HS state (by ca. $0.7 \mathrm{kHz}$ ). This finding is in agreement with previous results reported for the SCO-MEMS systems with $\left[\mathrm{Fe}\left(\mathrm{H}_{2} \mathrm{~B}(\mathrm{pz})_{2}\right)_{2}\right.$ (phen)] [11] and [ $\left.\mathrm{Fe}\left(\mathrm{HB}(\mathrm{tz})_{3}\right)_{2}\right]$ [12] spin crossover coatings. In the next step, we carried out more than 100 thermal cycles with simultaneous recording of the resonance frequency of the coated cantilever. Following a small drift during the first few cycles, the thermomechanical behavior of the MEMS devices turned out remarkably robust and well-reproducible (Figure 2c). When the temperature increases (resp. decreases) between $40^{\circ} \mathrm{C}$ and $130{ }^{\circ} \mathrm{C}$ the resonance frequency reversibly decreases (resp. increases) between $45,700 \pm 100 \mathrm{~Hz}$ and $49,600 \pm 100 \mathrm{~Hz}$. It shall be noted that this reversibility of dynamical MEMS properties upon cycling refers mostly to the robustness of the thermomechanical properties of the composite. On the other hand, the reversibility of the SCO properties is more clearly inferred from the static MEMS data (vide infra).
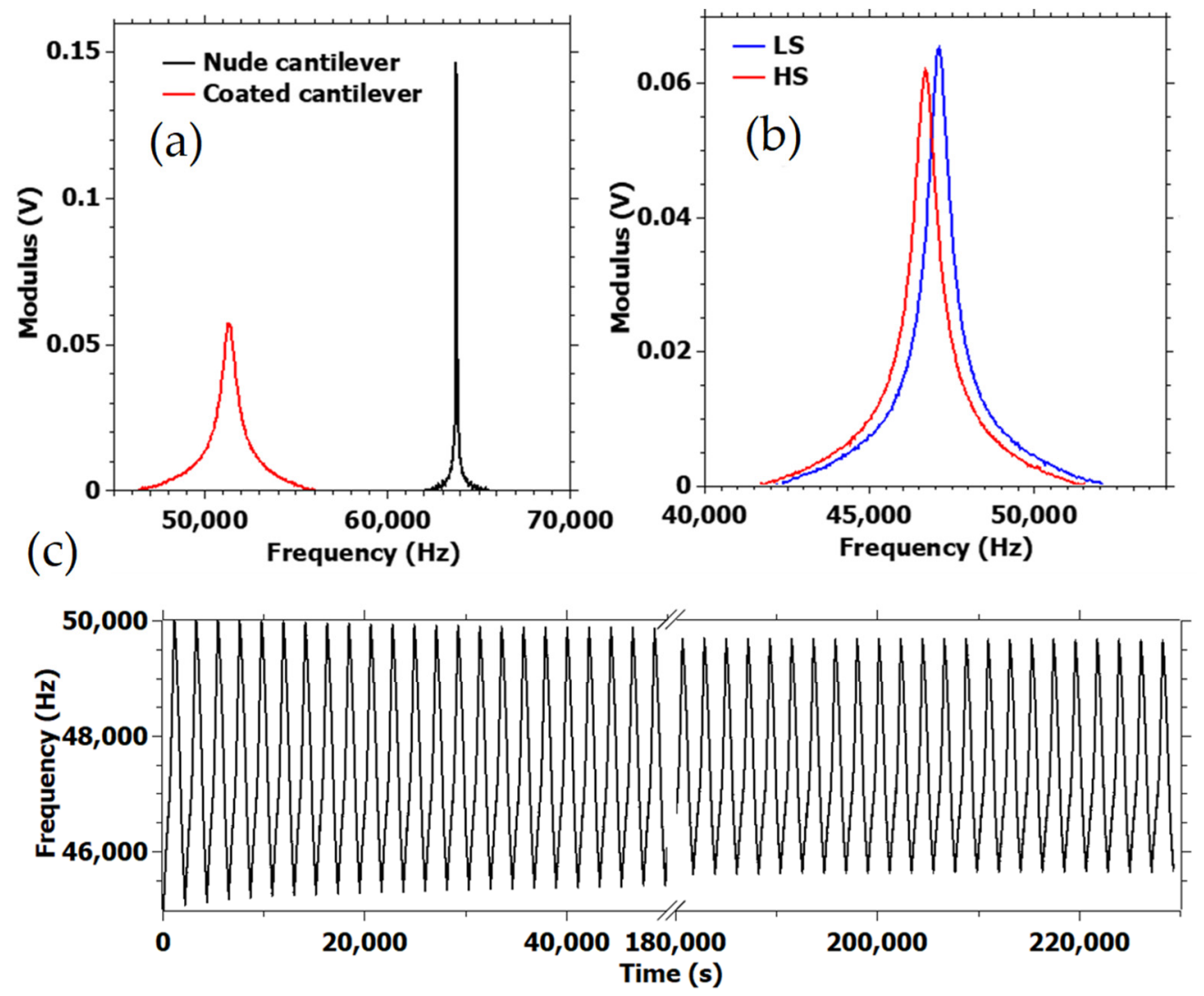

Figure 2. (a) Resonance peak of a cantilever before and after coating with a $1.5 \mu \mathrm{m}$-thick $\left[\mathrm{Fe}(\mathrm{Htrz})_{2}(\mathrm{trz})\right]\left(\mathrm{BF}_{4}\right) @ \mathrm{P}(\mathrm{VDF}-\mathrm{TrFE})$ composite film $\left(\mathrm{T}=25^{\circ} \mathrm{C}\right)$. (b) Resonance peak of the coated cantilever acquired in the LS and HS states within the hysteresis region $\left(\mathrm{T}=90^{\circ} \mathrm{C}\right)$. (c) Dynamic tracking of the MEMS resonance frequency for the coated cantilever upon 105 successive thermal cycles between $40-130{ }^{\circ} \mathrm{C}$.

The temperature-dependent static deflection of the cantilever coated with the nanocomposite material is compared with the behavior of the uncoated and $\mathrm{P}(\mathrm{VDF}-\mathrm{TrFE})$ coated cantilevers in Figure 3. The uncoated cantilever displays no substantial deflection in the investigated temperature range (Figure 3a). As can be expected, the bilayer cantilever, coated with the pure $\mathrm{P}(\mathrm{VDF}-\mathrm{TrFE})$ film, exhibits a downward bending-corresponding to an increase in the piezoresistance, $R$ (Figure $3 b$ ). On heating, the cantilever coated with 
the nanocomposite film exhibits first a similar, continuous downward bending due to the thermal expansion mismatch of the different layers (Figure 3c). However, one can depict a very clear hysteresis associated with the spin transition with an abrupt upward (downward) bending of the cantilever around $114^{\circ} \mathrm{C}\left(83^{\circ} \mathrm{C}\right)$ corresponding to the LSto-HS (HS-to-LS) transitions. Overall, ten thermal cycles were carried out to verify the reproducibility of the SCO actuation in the static regime. After the first heating ("run-in"), the amplitude of actuation becomes stable and perfectly reversible. The spin transition temperatures (extracted from the derivative curves $d R / d T$ ) in these experiments are slightly upshifted when compared to the transition temperatures recorded by variable temperature UV absorption measurements on the same film $\left(118^{\circ} \mathrm{C}\right.$ and $72{ }^{\circ} \mathrm{C}$, see Figure $\left.3 \mathrm{~d}\right)$, which occurs most likely due to the different thermalization conditions in the MEMS and optical absorbance measurements (freestanding cantilever in 5 mbar vacuum vs. film on substrate in $1 \mathrm{~atm}$ ambient air).
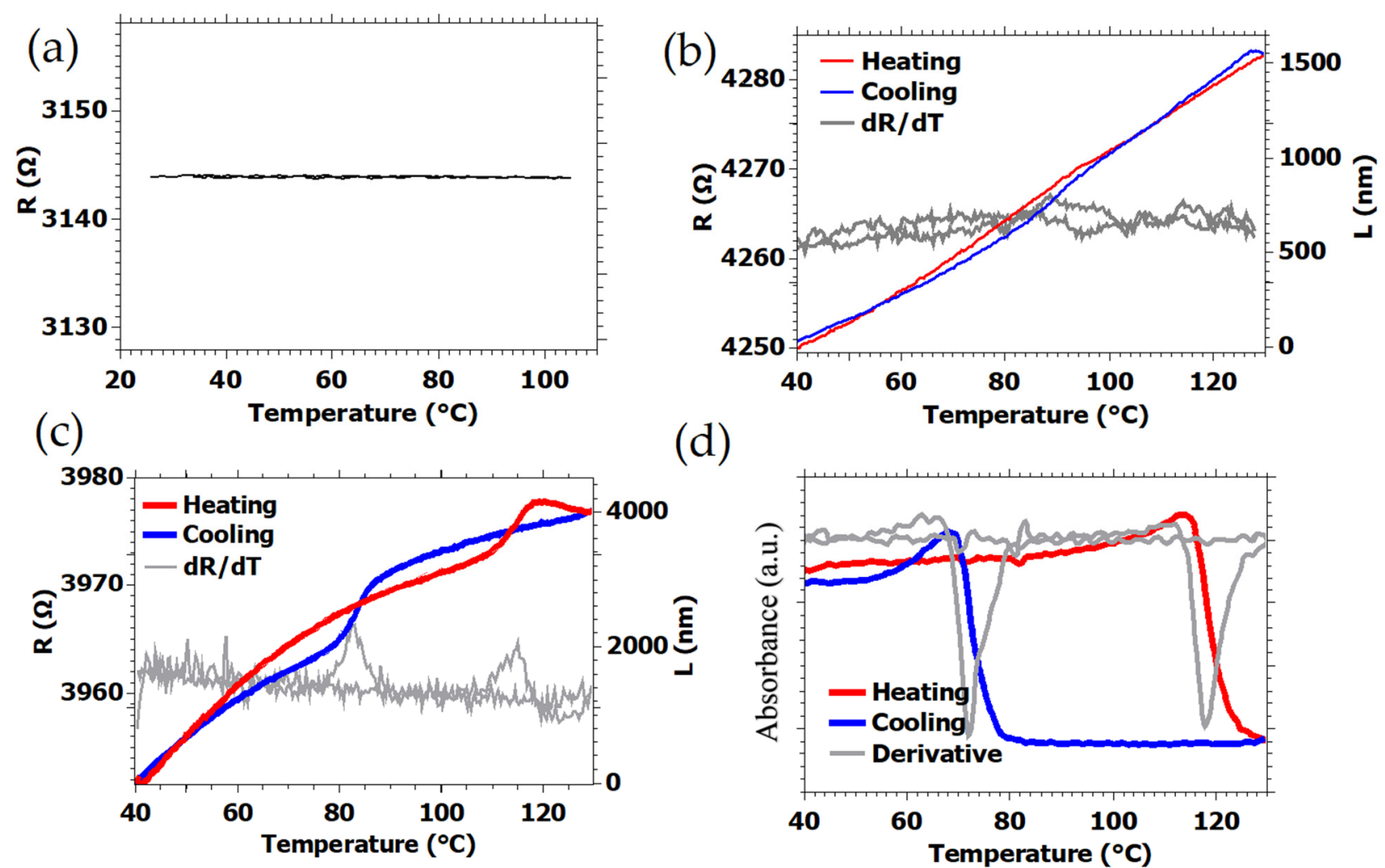

(d)

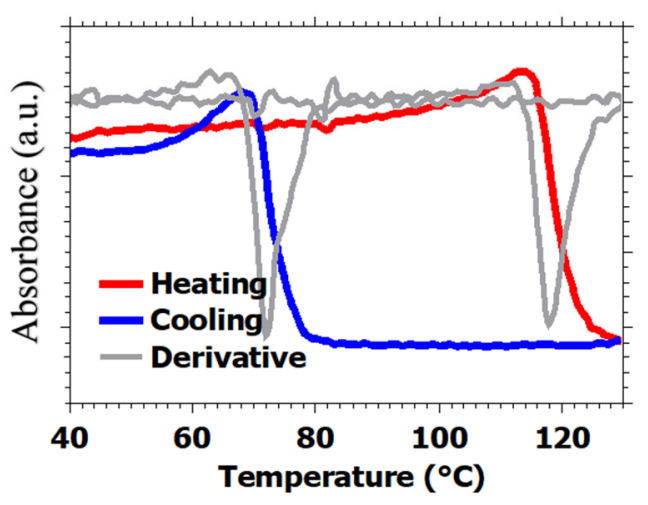

Figure 3. Actuating response upon heating and cooling of (a) an uncoated silicon micro-cantilever, (b) a microcantilever coated with a pure $\mathrm{P}(\mathrm{VDF}-\mathrm{TrFE})$ film, and $(\mathbf{c})$ a microcantilever coated with a $\left[\mathrm{Fe}(\mathrm{Htrz})_{2}(\mathrm{trz})\right]\left(\mathrm{BF}_{4}\right) @ \mathrm{P}(\mathrm{VDF}-\mathrm{TrFE})$ composite film. In $(\mathbf{b}, \mathbf{c})$ both the measured static piezoresistance change (left axis) and the calculated tip deflection (right axis) are given and the derivative curves ( $d R / d T$ vs. $T)$ are also plotted. (d) UV absorbance of a $\left[\mathrm{Fe}(\mathrm{Htrz})_{2}(\operatorname{trz})\right]\left(\mathrm{BF}_{4}\right) @ \mathrm{P}(\mathrm{VDF}-\mathrm{TrFE})$ composite film recorded at $350 \mathrm{~nm}$ both for heating and cooling. The derivative curve $(d A / d T$ vs. $T)$ is also shown.

\section{Discussion}

We used the MEMS dynamical data primarily to evaluate the Young's modulus of the spray-coated films. Indeed, the resonant angular frequency $(\omega)$ is determined by the geometry of the resonator and the mechanical properties of the materials used. For our (idealized) bilayer, single-clamped cantilever, the ratio of the resonance frequencies of the coated $\left(\omega_{f+s}\right)$ and uncoated $\left(\omega_{s}\right)$ cantilevers is given by [25]:

$$
\left(\frac{\omega_{f+s}}{\omega_{s}}\right)^{2}=\frac{\left(E_{r} t_{r}^{3}+1\right)\left(E_{r} t_{r}+1\right)+3 E_{r} t_{r}\left(t_{r}+1\right)^{2}}{\left(\rho_{r} t_{r}+1\right)\left(E_{r} t_{r}+1\right)}
$$


with $E$, $t$ and $\rho$ the Young's modulus, thickness and mass density, respectively. The subscript $r$ refers to the ratio between the film and substrate properties. As shown by Equation (1), the resonance shift (Figure 2a) is related primarily to changes in the Young's modulus, mass density and thickness of the resonator. In these calculations, we considered that the mechanical properties of the silicon cantilever are constant with temperature, which is a reasonable approximation for this small temperature range [26]. The model parameters for the silicon cantilever were $t=2 \mu \mathrm{m}, E=169 \mathrm{GPa}$ and $\rho=2330 \mathrm{~kg} / \mathrm{m}^{3}$. As shown in Table 1 the extracted Young's modulus $(E)$ of the SCO@P(VDF-TrFE) composite film is ca. 3.2 GPa at $40{ }^{\circ} \mathrm{C}$ and $0.5 \mathrm{GPa}$ at $95{ }^{\circ} \mathrm{C}$, respectively. This marked softening shows the same tendency as reported in [27] for the pure $\mathrm{P}\left(\mathrm{VDF}_{70}-\mathrm{TrFE}_{30}\right)$. We shall note here that, in principle, the resonance frequency shift upon the SCO (Figure $2 b$ ) could be used to assess the SCO-induced changes in mechanical properties. In our composite films, however, the spin transition in the particles and the Curie transition in the matrix occurs in nearly the same temperature range $\left(T_{\text {Curie }}=110^{\circ} \mathrm{C}\right.$ and $70^{\circ} \mathrm{C}$ on heating and cooling, respectively [20]). As a result, the MEMS dynamical behavior, which is governed chiefly by the matrix properties, did not allow us to discriminate the SCO phenomenon properly.

On the other hand, it turned out that the Curie transition has a much smaller effect on the static MEMS properties (Figure 3b), which were thus used to assess the actuating properties associated with the SCO. The two key equations, which are widely used for the analysis of the (quasi-static) flexural bending of thin film - substrate, bilayer beam systems have been developed by Timoshenko [28] and Stoney [29]. Timoshenko's theory was originally developed to model metal bimorphs that bend upon heating due to different coefficients of thermal expansion. However, it can be applied for other kinds of eigenstrains and can thus provide connection between the curvature of the bilayer cantilever $(k)$ and the actuation strain $\varepsilon_{S C O}$, associated with the $\mathrm{SCO}$ [8]:

$$
k=\frac{6(1+m)^{2}}{h\left[3\left(1+m^{2}\right)+(1+m n)\left(m^{2}+\frac{1}{m n}\right)\right]_{S C O}} \varepsilon
$$

where $m=t_{f} / t_{s}, n=E_{f} / E_{s}$ and $h=t_{f}+t_{s}$. The subscripts $s$ and $f$ stand for substrate and film, whereas $t$ and $E$ denote thickness and Young's modulus, respectively. For small tip deflections $(\delta)$, the beam curvature can be simply estimated as:

$$
k=\frac{2 \delta}{l^{2}}
$$

where $l$ is the beam length. Equations (2) and (3), together with the experimentally measured beam deflection (Figure 3c), beam geometry and Young's modulus data (extracted from the dynamical data using Equation (1) can then be used to determine the actuation strain.

On the other hand, Stoney's equation can be used to calculate the film stress $\sigma_{f}$ causing the beam curvature $k$ [29]:

$$
\sigma_{f}=\frac{-E_{s} t_{s}^{2}}{6\left(1-v_{s}\right) t_{f}} k
$$

where $v$ is the Poisson's coefficient $\left(v_{s i}=0.22\right)$. This equation provides good numerical results for thin films $\left(t_{f}<<t_{s}\right)$ deposited on rectangular plates $(z<<x, y)$.

At this point, we must note that the cantilevers are actually formed by three layers. The silicon base is electrically insulated by an $\mathrm{SiO}_{2}$ layer on top of which the SCO@P(VDF$\mathrm{TrFE}$ ) composite films are spray-coated. Metallic paths are also deposited on the $\mathrm{SiO}_{2}$ layer. In addition, preferential orientation of the rod-shaped particles can be expected, leading to anisotropic properties. Hence, the calculation results reported below, which refer to a bilayer beam with a thin, isotropic deposit, should be considered only as a relatively crude estimation of the actual material properties. 
For the spray-coated $\left.\left[\mathrm{Fe}(\mathrm{Htrz})_{2}(\mathrm{trz})\right] \mathrm{BF}_{4}\right) @ \mathrm{P}(\mathrm{VDF}-\mathrm{TrFE})$ composite film, the inputs and outputs of the Timoshenko and Stoney equations are shown in Table 1. The spin transition gives rise to a reversible tip displacement of $0.88 \mu \mathrm{m}$, which corresponds to a curvature change of ca. $80 \mathrm{~m}^{-1}$. This allows us to estimate the actuation strain, $\varepsilon_{\mathrm{SCO}}=1.3 \%$, the film stress associated with the $\mathrm{SCO}, \sigma_{S C O}=7.7 \mathrm{MPa}$ and the volumetric work density, $w / v=E \varepsilon_{S C O}{ }^{2} / 2=40 \mathrm{~mJ} / \mathrm{cm}^{3}$. It is instructive to compare these results with the precedent work of Manrique et al. [13], where the same SCO complex was used to spray-coat an SU8 epoxy-based composite on a MEMS cantilever with similar geometry. As shown in Table 1, we find similar actuation strain and lower values for the actuation stress and work density. The latter finding is obviously related to the fact that the Young's modulus of the epoxy composite is significantly higher (3.2 GPa) than that of the P(VDF-TrFE) (0.5 GPa) at the working temperature of the actuator.

\section{Materials and Methods}

$\left[\mathrm{Fe}(\mathrm{Htrz})_{2}(\mathrm{trz})\right]\left(\mathrm{BF}_{4}\right)$ particles were synthesized as described in [21]. Pellets of P(VDFTrFE) were provided by Piezotech. A dispersion of the SCO particles (33 wt \%) and P(VDFTrFE) in 2-butanone was spray-coated on the MEMS cantilevers using a SUSS MicroTec AltaSpray 8 manual spray-coater. Before the coating process, the cantilevers were cleaned by means of a Jelight UVO-Cleaner 42 UV-Ozone cleaning instrument. Details of the MEMS fabrication and operation principles are given in refs. [23,24], whereas the cantilever geometries are shown in Table 1. Briefly, for the dynamic measurements, the device was actuated at its resonance frequency by a magnetic field and the mechanical stress induced by the vibration of the cantilever was detected by integrated piezoresistors. Static measurements were conducted either separately or simultaneously with the dynamic measurements using the same piezoresistances. To quantify the amplitude of the actuation, the piezoresistance signal was calibrated by an external optical vibrometer [13]. To detect the actuation associated with the SCO phenomenon, the MEMS were cycled between $40^{\circ} \mathrm{C}$ and $130{ }^{\circ} \mathrm{C}$ using a HFS350V heating-cooling stage (Linkam Scientific). All experiments were conducted in a controlled vacuum pressure of 5 mbar.

\section{Conclusions}

A primary interest of our spray-coating approach is that the resulting films can be easily incorporated into complex micro- and nanosystems. Indeed, the spray-coating method allows depositing the films on practically any kind of surface, even if it displays high topography features. This advantage was clearly demonstrated in the present paper by spray-coating MEMS silicon micro-cantilevers with $\left[\mathrm{Fe}(\mathrm{Htrz})_{2}(\operatorname{trz})\right]\left(\mathrm{BF}_{4}\right) @ \mathrm{P}(\mathrm{VDF}-\mathrm{TrFE})$ composite films. The obtained bilayer cantilevers were then investigated for their dynamic (vibration) and static (deflection) thermomechanical properties, which were found to be highly reversible over more than 100 thermal cycles. From the dynamical data, we extracted the Young's modulus of the spray-coated composite, which was comparable with literature data. Most importantly, we evidenced a reproducible actuation around the spin transition temperatures in the composite with an actuation strain of $\sim 1.3 \%$, an actuation stress of $\sim 7.7 \mathrm{MPa}$ and a work density of $\sim 40 \mathrm{~mJ} / \mathrm{cm}^{3}$. These results provide proof for the conservation of the attractive thermal actuating properties of the particles in the thin, spray-coated films. Further work is planned to exploit this actuation in conjunction with the piezoelectric properties of the matrix for thermal energy harvesting purposes.

Author Contributions: Conceptualization: A.B., methodology: T.L. and L.N., investigation: J.E.A.-C., F.M., M.P.-B., data analysis: J.E.A.-C., F.M., L.S., G.M., funding acquisition: L.S., A.B., supervision: G.M., L.N., T.L., A.B., writing-original draft: J.E.A.-C., G.M. All authors have read and agreed to the published version of the manuscript.

Funding: This work was supported by the CONACyT-Mexico (PhD grant 471690 of J.E.A.-C.) and the Occitanie Region/Federal University of Toulouse (PhD grant of MPB), the ANR-France (19-CE09-0008-01), and by the LAAS-CNRS technology platform, a member of Renatech network. 
Institutional Review Board Statement: Not applicable.

Informed Consent Statement: Not applicable.

Data Availability Statement: Data is available from the authors on reasonable request.

Conflicts of Interest: The authors declare no conflict of interest.

\section{References}

1. Gütlich, P.; Hauser, A.; Spiering, H. Thermal and Optical Switching of Iron(II) Complexes. Angew. Chem. Int. Ed. 1994, 33, 2024-2054. [CrossRef]

2. Gütlich, P.; Goodwin, H.A. Spin Crossover in Transition Metal Compounds I-III; Springer: Berlin/Heidelberg, Germany, 2004; Volume 233-235.

3. Bousseksou, A.; Molnar, G.; Salmon, L.; Nicolazzi, W. Molecular spin crossover phenomenon: Recent achievements and prospects. Chem. Soc. Rev. 2011, 40, 3313-3335. [CrossRef] [PubMed]

4. Halcrow, M.A. (Ed.) Spin-Crossover Materials: Properties and Applications; John Wiley \& Sons: Oxford, UK, 2013.

5. Collet, E.; Guionneau, P. Structural analysis of spin-crossover materials: From molecules to materials. Comptes Rendus Chim. 2018, 21, 1133-1151. [CrossRef]

6. Guionneau, P. Crystallography and spin-crossover. A view of breathing materials. Dalton Trans. 2014, 43, 382-393. [CrossRef] [PubMed]

7. Halcrow, M. Structure:function relationships in molecular spin-crossover complexes. Chem. Soc. Rev. 2011, 40, 4119-4142 [CrossRef]

8. Shepherd, H.J.; Gural'Skiy, I.A.; Quintero, C.M.; Tricard, S.; Salmon, L.; Molnar, G.; Bousseksou, A. Molecular actuators driven by cooperative spin-state switching. Nat. Commun. 2013, 4, 2607. [CrossRef]

9. Gural'Skiy, I.A.; Quintero, C.M.; Costa, J.S.; Demont, P.; Molnar, G.; Salmon, L.; Shepherd, H.; Bousseksou, A. Spin crossover composite materials for electrothermomechanical actuators. J. Mater. Chem. C 2014, 2, 2949-2955. [CrossRef]

10. Chen, Y.-C.; Meng, Y.; Ni, Z.-P.; Tong, M.-L. Synergistic electrical bistability in a conductive spin crossover heterostructure. J. Mater. Chem. C 2014, 3, 945-949. [CrossRef]

11. Manrique-Juarez, M.D.; Rat, S.; Mathieu, F.; Saya, D.; Séguy, I.; Leïchlé, T.; Nicu, L.; Salmon, L.; Molnar, G.; Bousseksou, A. Microelectromechanical systems integrating molecular spin crossover actuators. Appl. Phys. Lett. 2016, 109, 061903. [CrossRef]

12. Manrique-Juarez, M.D.; Mathieu, F.; Shalabaeva, V.; Cacheux, J.; Rat, S.; Nicu, L.; Leïchlé, T.; Salmon, L.; Molnár, G.; Bousseksou, A. A Bistable Microelectromechanical System Actuated by Spin-Crossover Molecules. Angew. Chem. Int. Ed. 2017, 56, 8074-8078. [CrossRef]

13. Manrique-Juárez, M.D.; Mathieu, F.; Laborde, A.; Rat, S.; Shalabaeva, V.; Demont, P.; Thomas, O.; Salmon, L.; Leïchlé, T.; Nicu, L.; et al. Micromachining-Compatible, Facile Fabrication of Polymer Nanocomposite Spin Crossover Actuators. Adv. Funct. Mater. 2018, 28, 1801970. [CrossRef]

14. Mikolasek, M.; Manrique-Juarez, M.D.; Shepherd, H.J.; Ridier, K.; Rat, S.; Shalabaeva, V.; Bas, A.-C.; Collings, I.E.; Mathieu, F.; Cacheux, J.; et al. Complete Set of Elastic Moduli of a Spin-Crossover Solid: Spin-State Dependence and Mechanical Actuation. J. Am. Chem. Soc. 2018, 140, 8970-8979. [CrossRef]

15. Urdampilleta, M.; Ayela, C.; Ducrot, P.-H.; Rosario-Amorin, D.; Mondal, A.; Rouzières, M.; Dechambenoit, P.; Mathonière, C.; Mathieu, F.; Dufour, I.; et al. Molecule-based microelectromechanical sensors. Sci. Rep. 2018, 8, 1-6. [CrossRef]

16. Dugay, J.; Giménez-Marqués, M.; Venstra, W.J.; Torres-Cavanillas, R.; Sheombarsing, U.N.; Manca, N.; Coronado, E.; Van Der Zant, H.S.J. Sensing of the Molecular Spin in Spin-Crossover Nanoparticles with Micromechanical Resonators. J. Phys. Chem. C 2019, 123, 6778-6786. [CrossRef]

17. Piedrahita-Bello, M.; Angulo-Cervera, J.E.; Courson, R.; Molnár, G.; Malaquin, L.; Thibault, C.; Tondu, B.; Salmon, L.; Bousseksou, A. 4D printing with spin-crossover polymer composites. J. Mater. Chem. C 2020, 8, 6001-6005. [CrossRef]

18. Molnár, G.; Rat, S.; Salmon, L.; Nicolazzi, W.; Bousseksou, A. Spin Crossover Nanomaterials: From Fundamental Concepts to Devices. Adv. Mater. 2018, 30, 1703862. [CrossRef]

19. Rat, S.; Piedrahita-Bello, M.; Salmon, L.; Molnár, G.; Demont, P.; Bousseksou, A. Coupling Mechanical and Electrical Properties in Spin Crossover Polymer Composites-Supporting information. Adv. Mater. 2018, 30, 1705275. [CrossRef]

20. Piedrahita-Bello, M.; Martin, B.; Salmon, L.; Molnár, G.; Demont, P.; Bousseksou, A. Mechano-Electric coupling in P(VDFTrFE)/spin crossover composites. J. Mater. Chem. C 2020, 8, 6042-6051. [CrossRef]

21. Suleimanov, I.; Costa, J.S.; Molnár, G.; Salmon, L.; Fritsky, I.; Bousseksou, A. Effect of ligand substitution in [Fe(H-trz)2(trz)]BF4 spin crossover nanoparticles. Fr. Ukr. J. Chem. 2015, 3, 66-72. [CrossRef]

22. Létard, J.-F.; Guionneau, P.; Goux-Capes, L. Towards Spin Crossover Applications. Top. Curr. Chem. 2006, 235, 221-249. [CrossRef]

23. Alava, T.; Mathieu, F.; Mazenq, L.; Soyer, C.; Remiens, D.; Nicu, L. Silicon-Based micromembranes with piezoelectric actuation and piezoresistive detection for sensing purposes in liquid media. J. Micromech. Microeng. 2010, 20, 075014. [CrossRef]

24. Dufour, I.; Maali, A.; Amarouchene, Y.; Ayela, C.; Caillard, B.; Darwiche, A.; Guirardel, M.; Kellay, H.; Lemaire, E.; Mathieu, F.; et al. The Microcantilever: A Versatile Tool for Measuring the Rheological Properties of Complex Fluids. J. Sens. 2012, 2012, 719898. [CrossRef] 
25. Whiting, R.; Angadi, M.; Tripathi, S. Evaluation of elastic moduli in thin-film/substrate systems by the two-layer vibrating reed method. Mater. Sci. Eng. B 1995, 30, 35-38. [CrossRef]

26. Vanhellemont, J.; Swarnakar, A.K.; Van Der Biest, O. Temperature Dependent Young's Modulus of Si and Ge. ECS Trans. 2014, 64, 283-292. [CrossRef]

27. Hafner, J.; Teuschel, M.; Schneider, M.; Schmid, U. Origin of the strong temperature effect on the piezoelectric response of the ferroelectric (co-)polymer P(VDF70-TrFE30). Polymer 2019, 170, 1-6. [CrossRef]

28. Timoshenko, S. Analysis of Bi-Metal Thermostats. J. Opt. Soc. Am. 1925, 11, 233-255. [CrossRef]

29. Stoney, G.G. The tension of metallic films deposited by electrolysis. Proc. R. Soc. London. Ser. A Math. Phys. Sci. 1909, 82, $172-175$. [CrossRef] 